\title{
ANALISIS PENGGUNAAN ACCESS CONTROL LIST (ACL) DALAM JARINGAN KOMPUTER DI KAWASAN BATAMINDO INDUSTRIAL PARK BATAM
}

\author{
Pastima Simanjuntak $^{1}$, Cosmas Eko Suharyanto ${ }^{2}$, Jamilah $^{3}$ \\ Fakultas Teknik Universitas Putera Batam \\ Email: p.lastria@gmail.com
}

\begin{abstract}
Routers provide the ability to filter traffic, such as blocking Internet traffic, with access Control Lists (ACLs). ACL is a list of a series of licensing or rejection statement applied to the network address or protocol layer on top. The purpose of this study is to determine the effect of the access control list in the area of network computer in Batamindo Industrial Park Batam. The method used in this research is descriptive and verification methods. The samples are 101 IT employees in Batamindo Industrial Park Batam. And in the formulation of the problem obtained from this research is to determine how the benefits of the use of access control lists. The results obtained are perceived first access control list useful, both instrumental Well Network computer, So with this research writer and IT Employees in the Company may determine that the use of access control lists is very important for computer networks in the area Batamindo Industrial Park Batam.
\end{abstract}

Keywords: Access Control List and Network

\begin{abstract}
ABSTRAK
Router menyediakan kemampuan untuk menyaring traffic, seperti memblokir traffic Internet, dengan Access Control Lists ( ACL). ACL adalah suatu rentetan list dari suatu statemen perijinan atau penolakan yang di aplikasikan kepada alamat-alamat jaringan atau layer protokol paling atas. Tujuan dari penelitian ini yaitu untuk mengetahui pengaruh access control list dalam jaringan di Kawasan Batamindo Industrial Park Batam. Metode yang digunakan dalam penelitian ini adalah metode deskriptif. Sampel yang digunakan sebanyak 101 karyawan IT di Batamindo Industrial Park Batam. Dan di peroleh rumusan masalah dari penelitian ini yaitu untuk menentukan bagaimana manfaat penggunaan access control list. Hasil penelitian yang diperoleh adalah access control list dipersepsikan bermanfaat, Maka dengan penelitian ini penulis dan Karyawan IT di Perusahaan dapat mengetahui bahwa penggunaan access control list sangat penting dalam jaringan komputer di Kawasan Batamindo Industrial Park Batam.
\end{abstract}

Kata Kunci: Access Control List and Jaringan Komputer. 


\section{PENDAHULUAN}

Kawasan industri Batamindo adalah kawasan industri yang berada di Muka Kuning dengan luas wilayah sekitar 320 Ha dan merupakan Kawasan industri pertama yang terbesar dan terbaik di Batam sejak beroperasi tahun 1990. Mulai dari tahun 2000 nama kawasan industri ini berubah menjadi Batamindo Investment Cakrawala (BIC).Sejarah Batamindo berasal dari perjanjian kerjasama ekonomi antara pemerintah Indonesia dan Singapura pada tahun 1989. Di kawasan ini terdapat sekitar 100 perusahaan yang beroperasional dengan mayoritas perusahaan asing, yang juga membuka cabang di Indonesia.

Salah satu bentuk permasalahan dalam jaringan komputer pada berbagai perusahaan di Kawasan Industri Batamindo adalah sering terjadinya serangan-serangan terhadap jaringan komputer. Maka dengan latar belakang masalah dibutuhkan suatu pengaturan keamanan jaringan untuk mengontrol akses-akses diantara jaringan yang dihubungkan router, atau menetapkan jenis traffic tertentu yang diijinkan untuk lepas ke dan dari sebuah jaringan yang dipergunakan yaitu dengan menggunakan access control list yang berada di setiap router yang ada di perusahaan.

Router menyediakan kemampuan untuk menyaring traffic, seperti memblokir traffik internet, dengan Access Control Lists ( ACL). ACL adalah suatu rentetan list dari suatu statemen perijinan atau penolakan yang di aplikasikan kepada alamat-alamat jaringan atau layer protokol paling atas. Terdapat dua tipe ACL yaitu standard ACL dan Extended ACL sebagai cara untuk mengendalikan traffik jaringan dan menjelaskan kegunaan keamanan jaringan digunakan sebagai bagian dari suatu solusi keamanan. ACL bisa digambarkan seperti garis tunggal yang mengijinkan paket-paket data dari host atau ACL dapat juga diartikan sekumpulan aturanaturan yang komplek dan kondisi yang menggambarkan traffik jaringan dan menentukan proses routing.

Access control list (ACL), merupakan pengelompokan paket berdasarkan kategori. Access Control List (ACL) bisa sangat membantu ketika membutuhkan pengontrolan dalam lalu lintas network. Access control list menjadi tool pilihan untuk pengambilan keputusan pada situasi ini. Access Control List (ACL) sederhananya digunakan untuk mengijinkan atau tidak paket dari host menuju ke tujuan tertentu. Access Control List (ACL) terdiri atas aturan-aturan dan kondisi yang menentukan trafik jaringan dan menentukan proses di router apakah nantinya paket akan dilewatkan atau tidak. Penggunaan access Control list (ACL) yang paling umum dan paling mudah untuk dimengerti adalah penyaringan paket yang tidak diinginkan ketika mengimplementasikan kebijakan keamanan.

Tujuan dalam penelitian ini adalah untuk mengetahui manfaat penggunaan Access Control List (ACL) pada perusahaan di Kawasan Batamindo Industrial Park Batam?

Access Control List (ACL) merupakan sebuah metode yang digunakan untuk menyeleksi paket-paket yang keluar masuk network. Cisco memberikan kapasitas-kapasitas traffic filtering melalui fitur yang dikenal Access Control List (ACL) atau di singkat access list. Access list dapat dikonfigurasikan untuk semua protokol jaringan (IP, AppleTalk, dan lain-lain), dengan demikian kita bisa memfilter paket-paket yang melintasi router berdasarkan protokol tersebut. ${ }^{[1]}$ 
Adapun indikator-indikator access control list (ACL) pada penelitian ini yaitu (1) Access-list, (2) List Number (3) Permit/deny, (4) Protocol, (5) Source specification,(6)

Destination specification, (7) Protocol qualification, (8) Log/loging. ${ }^{[1]}$

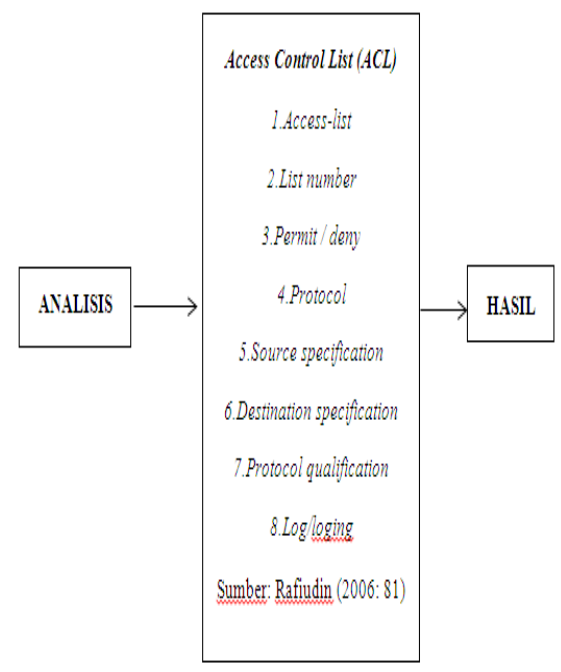

Gambar 1. Kerangka Pemikiran

\section{METODE PENELITIAN \\ Desain Penelitian}

Desain dari penelitian adalah semua proses yang diperlukan dalam perencanaan dan pelaksanaan penelitian. Dalam pengertian yang lebih sempit, desain penelitian hanya mengenai pengumpulan dan analisis data saja. Dalam merencanakan penelitian, desain dimulai dengan mengadakan penyelidikan dan evaluasi terhadap penelitian yang sudah dikerjakan dan diketahui, dalam memecahkan masalah. Dari penyelidikan ini, akan terjawab bagaimana hipotesis dirumuskan dan diuji dengan data yang diperoleh untuk memecahkan suatu masalah. Dari sini pula dapat dicari beberapa petunjuk tentang desain yang akan dibuat untuk penelitian yang akan dikembangkan. Pemilihan desain biasanya dimulai ketika seorang peneliti sudah mulai merumuskan hipotesisnya. Desain penelitian yang baik akan menerjemahkan model kedalam operasional secara praktis. ${ }^{[2]}$

Variable yang akan di teliti oleh penulis yaitu access control list dalam keamanan jaringan yang akan di teliti menggunakan metode analisis deskriptif. ${ }^{[3]}$ Populasi pada penelitian ini adalah karyawan bagian IT pada perusahaan-perusahaan di Kawasan Batamindo Industrial Park Batam, sebanyak 101 Karyawan Bagian IT Dari keseluruhan populasi yang ada, yang akan dijadikan sampel untuk penelitian.

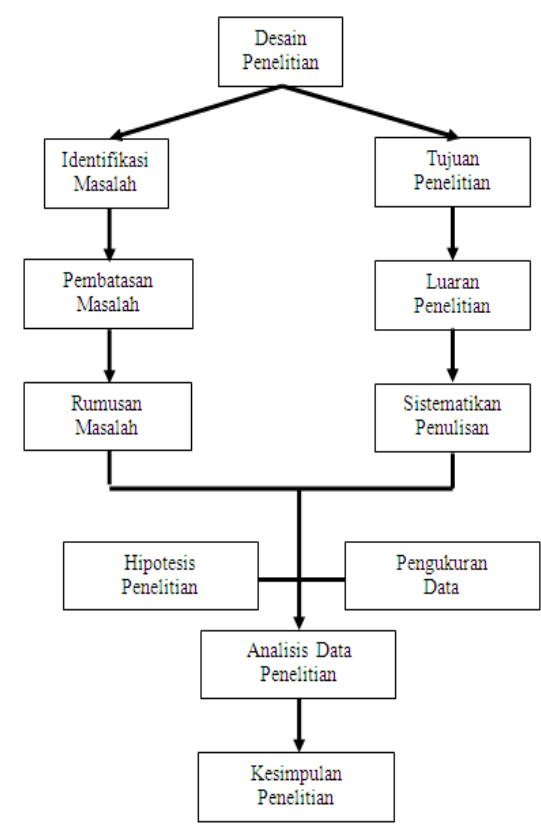

Gambar 2. Desain Penelitian

\section{HASIL DAN PEMBAHASAN}

Penelitian ini bertujuan untuk mengetahui persepsi dari pengguna bagaimana manfaat penggunaan Access Control List (ACL) pada perusahaan di Kawasan Batamindo Industrial Park Batam. Untuk menjawab permasalahan tersebut, peneliti melakukan analisis deskriptif. Berdasarkan data yang diperoleh melalui angket / kuesioner, selanjutnya akan diolah dengan program 
statistik yaitu statistical package for the social science (SPSS) release 19. Adapun langkah awal untuk menentukan hasil penelitian adalah dengan melakukan analisis deskriptif. ${ }^{[4]}$

Tabel 1.Data Responden Berdasarkan Perusahaan

\begin{tabular}{|c|c|c|}
\hline Nama Perusahaan & $\begin{array}{l}\text { Frequ } \\
\text { ency }\end{array}$ & Percent \\
\hline $\begin{array}{l}\text { PT Alteco Chemical } \\
\text { Indonesia }\end{array}$ & 1 & 1 \\
\hline $\begin{array}{l}\text { PT Asiatech } \\
\text { Manufacturing Indonesia }\end{array}$ & 2 & 2 \\
\hline $\begin{array}{l}\text { PT Birotika Semesta } \\
\text { (DHL Express) }\end{array}$ & 2 & 2 \\
\hline PT CIBA V1ision Batam & 3 & 3 \\
\hline PT Daihan Labtech & 2 & 2 \\
\hline PT Dynacast Indonesia & 2 & 2 \\
\hline $\begin{array}{l}\text { PT E-Tech Manufacturing } \\
\text { Indonesia }\end{array}$ & 1 & 1 \\
\hline PT Epson Batam & 3 & 3 \\
\hline PT Cicor Panatec & 2 & 2 \\
\hline PT Esqarada/BSW & 2 & 2 \\
\hline $\begin{array}{l}\text { PT Kemet Electronics } \\
\text { Indonesia }\end{array}$ & 1 & 1 \\
\hline PT EX Batam Indonesia & 1 & 1 \\
\hline $\begin{array}{l}\text { PT Excelitas } \\
\text { Technologies Batam }\end{array}$ & 2 & 2 \\
\hline $\begin{array}{l}\text { PT Flextronics } \\
\text { Technology Indonesia }\end{array}$ & 2 & 2 \\
\hline PT Fluid Sciences Batam & 2 & 2 \\
\hline $\begin{array}{l}\text { PT Foster Electric } \\
\text { Indonesia }\end{array}$ & 2 & 2 \\
\hline PT Fujitec Indonesia & 2 & 2 \\
\hline $\begin{array}{l}\text { PT GreenLam Asia } \\
\text { Pacific }\end{array}$ & 2 & 2 \\
\hline PT HLN Batam & 2 & 2 \\
\hline PT Hymold Batam & 1 & 1 \\
\hline $\begin{array}{l}\text { PT Honfoong Plastic } \\
\text { Industries }\end{array}$ & 1 & 1 \\
\hline $\begin{array}{l}\text { PT Infineon Technologies } \\
\text { Batam }\end{array}$ & 5 & 5 \\
\hline PT Intricon Indonesia & 1 & 1 \\
\hline $\begin{array}{l}\text { PT Indonesia Bearing } \\
\text { Factory }\end{array}$ & 1 & 1 \\
\hline PT JMS Batam & 1 & 1 \\
\hline PT Japan Servo Batam & 1 & 1 \\
\hline PT Jotun Indonesia & 1 & 1 \\
\hline PT Leo Industries Batam & 1 & 1 \\
\hline $\begin{array}{l}\text { PT Manuli Fluiconnecto } \\
\text { Batam }\end{array}$ & 1 & 1 \\
\hline
\end{tabular}

\begin{tabular}{|c|c|c|}
\hline $\begin{array}{l}\text { PT Nagano Drilube } \\
\text { Indonesia }\end{array}$ & 1 & 1 \\
\hline PT Nissin Kogyo Batam & 1 & 1 \\
\hline PT Noble Batam & 1 & 1 \\
\hline PT NOK Asia Batam & 2 & 2 \\
\hline $\begin{array}{l}\text { PT NOK Precision } \\
\text { Component Batam }\end{array}$ & 2 & 2 \\
\hline PT Patlite Indonesia & 2 & 2 \\
\hline $\begin{array}{l}\text { PT PCI Electronik } \\
\text { Internasional }\end{array}$ & 1 & 1 \\
\hline $\begin{array}{l}\text { PT Petrolog Harapan } \\
\text { Abadi Semesta }\end{array}$ & 1 & 1 \\
\hline PT Primo Microphones & 1 & 1 \\
\hline PT Rapala VMC Batam & 2 & 2 \\
\hline PT Risis Indonesia & 1 & 1 \\
\hline PT Riso Seiki Indonesia & 2 & 2 \\
\hline PT Rubycon Indonesia & 2 & 2 \\
\hline PT Sanipak Indonesia & 2 & 2 \\
\hline PT Sanmina - SCI Batam & 1 & 1 \\
\hline $\begin{array}{l}\text { PT Sansyu Precision } \\
\text { Batam }\end{array}$ & 1 & 1 \\
\hline $\begin{array}{l}\text { PT Sanwa Engineering } \\
\text { Batam }\end{array}$ & 1 & 1 \\
\hline PT Sanyo Energy Batam & 1 & 1 \\
\hline PT Nidec Seimitsu Batam & 1 & 1 \\
\hline $\begin{array}{l}\text { PT Schneider Electric } \\
\text { Manufacturing Batam }\end{array}$ & 3 & 3 \\
\hline PT Shimano Batam & 1 & 1 \\
\hline $\begin{array}{l}\text { PT Siemens Hearing } \\
\text { Instrument Batam }\end{array}$ & 1 & 1 \\
\hline $\begin{array}{l}\text { PT SIIX Electronics } \\
\text { Indonesia }\end{array}$ & 1 & 1 \\
\hline $\begin{array}{l}\text { PT Soxal Batamindo } \\
\text { Industrial Gases }\end{array}$ & 2 & 2 \\
\hline $\begin{array}{l}\text { PT Surya Teknologi } \\
\text { Batam }\end{array}$ & 2 & 2 \\
\hline $\begin{array}{l}\text { PT Teckwah Paper } \\
\text { Products Indonesia }\end{array}$ & 1 & 1 \\
\hline PT Unisem & 5 & 5 \\
\hline $\begin{array}{l}\text { PT Varta Microbatterry } \\
\text { Indonesia }\end{array}$ & 2 & 2 \\
\hline $\begin{array}{l}\text { PT Venturindo Jaya } \\
\text { Batam }\end{array}$ & 2 & 2 \\
\hline $\begin{array}{l}\text { PT VMC Fishing Tackle } \\
\text { Indonesia }\end{array}$ & 1 & 1 \\
\hline $\begin{array}{l}\text { PT Yeakin Plastic } \\
\text { Industry }\end{array}$ & 2 & 2 \\
\hline $\begin{array}{l}\text { PT Yokogawa } \\
\text { Manufacturing Batam }\end{array}$ & 2 & 2 \\
\hline Total & 101 & 100,0 \\
\hline
\end{tabular}

Dari data pada tabel 1 diatas, dapat diketahui bahwa total penelitian ini 
berjumlah 101 Responden, Responden terbesar ada pada PT.Infineon Technologies Batam dan PT.Unisem sebanyak 5 orang dengan persentase $5 \%$.

Tabel 2. Data Responden Berdasarkan Jenis Kelamin.

\begin{tabular}{|c|c|c|c|}
\hline \multirow{2}{*}{\multicolumn{2}{|c|}{\begin{tabular}{|l} 
Jenis \\
Kelamin
\end{tabular}}} & \multirow[t]{2}{*}{ Frequency } & \multirow[t]{2}{*}{ Percent } \\
\hline & & & \\
\hline \multirow{3}{*}{ Valid } & Pria & 96 & 95,0 \\
\hline & Wanita & 5 & 5,0 \\
\hline & Total & 101 & 100,0 \\
\hline
\end{tabular}

Dari data pada tabel 2 di atas, dapat diketahui bahwa total penelitian ini berjumlah 101 Responden. Jumlah responden laki-laki sebanyak 96 orang dengan persentase 95\%. Dan jumlah persentase perempuan sebanyak 5 orang dengan persentase 5\%. Hal ini menunjukan bahwa responden perempuan lebih sedikit dibanding dengan responden laki-laki.

Tabel 3. Data Responden Berdasarkan Usia.

\begin{tabular}{|rlrr|}
\hline & Usia & Frequency & Percent \\
& $<=25$ & 9 & 8,9 \\
Valid & $26-35$ & 66 & 65,3 \\
& $36-45$ & 21 & 20,8 \\
& $>=45$ & 5 & 5,0 \\
& Total & 101 & 100,0 \\
\hline
\end{tabular}

Dari data tabel 3 di atas dapat diketahui bahwa total penelitian ini berjumlah 101 responden, jumlah responden umur dibawah $\leq 25$ tahun sebanyak 9 orang dengan persentase $8,9 \%$, jumlah responden umur antara 26-35 tahun sebanyak 66 orang dengan persentase $65,3 \%$, jumlah responden umur antara 36-45 tahun sebanyak 21 orang dengan persentase $20,8 \%$, dan usia $\geq 45$ tahun sebanyak 5 orang dengan persentase $5 \%$. Hal ini menunjukkan bahwa responden usia antara 26-35 tahun lebih banyak dibanding dengan usia responden lainnya.
Tabel 4. Data Responden Berdasarkan Pendidikan.

\begin{tabular}{|crrr|}
\hline \multicolumn{3}{|c}{ Pendidikan } & \multicolumn{2}{c|}{ Percent } \\
& Diploma & 27 & 26,7 \\
& Sarjana & 66 & 65,3 \\
\multirow{4}{*}{ Valid } & Magister & 8 & 8,0 \\
& Diploma & 27 & 26,7 \\
& Total & 101 & 100,0 \\
& & & \\
\hline
\end{tabular}

Dari data pada tabel 4 diatas, dapat diketahui bahwa total penelitian ini berjumlah 101 Responden, jumlah responden dengan pendidikan Diploma (D3) sebanyak 27 orang dengan persentase $26,7 \%$, responden dengan pendidikan Sarjana (S1) sebanyak 66 orang dengan persentase $65,3 \%$, dan jumlah responden pendidikan Magister (S2) sebanyak 8 orang dengan persentase $8 \%$. Hal ini menunjukkan bahwa responden dengan tingkat pendidikan Sarjana lebih banyak dibanding dengan tingkat pendidikan responden lainnya.

Tabel 5. Hasil Uji Validitas Variabel Access Control List

\begin{tabular}{|c|c|c|c|}
\hline Kuesioner & Nilai $r$ hitung & Nilai $r$ tabel & Keterangan \\
\hline $\mathrm{X} 1$ & 0,682 & \multirow{8}{*}{0,194} & Valid \\
\hline $\mathrm{X} 2$ & 0,592 & & Valid \\
\hline X3 & 0,463 & & Valid \\
\hline $\mathrm{X} 4$ & 0,530 & & Valid \\
\hline $\mathrm{X} 5$ & 0,359 & & Valid \\
\hline $\mathrm{X} 6$ & 0,540 & & Valid \\
\hline $\mathrm{X} 7$ & 0,307 & & Valid \\
\hline X8 & 0,295 & & Valid \\
\hline
\end{tabular}

Dari hasil uji validitas pada variabel Access Control List (X) terlihat bahwa semua item skor dari setiap pernyataan adalah $r$ hitung $>r$ tabel $(0,194)$, hal ini menjelaskan bahwa setiap instrumen dari item pernyataan dinyatakan adalah valid. Dengan demikian maka delapan item pernyataan dari access control list (X) dinyatakan valid dan dapat digunakan dalam pengujian selanjutnya. 
Tabel 5. Hasil Uji Reliabilitas Variabel Access Control List

\begin{tabular}{|c|c|c|}
\hline \multicolumn{3}{|c|}{ Reliability Statistics } \\
\hline $\begin{array}{l}\text { Cronbach's } \\
\text { Alpha }\end{array}$ & $\begin{array}{l}\text { Cronbach's } \\
\text { Alpha Based on } \\
\text { Standardized } \\
\text { Items }\end{array}$ & $\mathrm{N}$ of Items \\
\hline, 762 &, 772 & 8 \\
\hline
\end{tabular}

Dari hasil perhitungan yang terlihat pada tabel 6 diatas, nilai Cronbach's Alpha dari uji reliabilitas adalah 0.762 yakni lebih besar dari 0.60. dengan demikian dapat dinyatakan bahwa instrument variabel penggunaan access control list dapat dipercaya (reliable).

Tabel 7. Hasil Analisis Deskriptif Variabel Access Control List (ACL)

\begin{tabular}{|c|c|c|c|}
\hline No & $\begin{array}{c}\text { Access Control } \\
\text { List }(A C L)\end{array}$ & $\begin{array}{l}\text { Total } \\
\text { Skor }\end{array}$ & $\begin{array}{c}\text { Kontri } \\
\text { busi }\end{array}$ \\
\hline 1 & $\begin{array}{lr}\text { Access-list } & \\
\text { beroperasi } & \text { secara } \\
\text { praktis dalam } & \text { danembaca dan } \\
\text { mengamati } & \text { paket- } \\
\text { paket dari jaringan }\end{array}$ & 391 & $9,68 \%$ \\
\hline 2 & $\begin{array}{l}\text { Nomor Access } \\
\text { Control List }(\text { ACL) } \\
\text { yang di berikan } \\
\text { sudah berada } \\
\text { dalam range yang } \\
\text { sudah di tentukan. }\end{array}$ & 374 & $9,26 \%$ \\
\hline 3 & \begin{tabular}{lr}
\multicolumn{3}{l}{ Suatu paket bisa di } \\
ijinkan atau di \\
blok & sesuai \\
dengan & entri \\
spesifikasi & yang \\
diberikan & \\
\end{tabular} & 388 & $9,60 \%$ \\
\hline 4 & $\begin{array}{l}\text { Access control list } \\
(A C L) \text { mampu } \\
\text { mengontrol paket- } \\
\text { paket berdasarkan } \\
\text { jenis protocol }\end{array}$ & 368 & $9,11 \%$ \\
\hline 5 & $\begin{array}{lr}\text { Suatu } & \text { paket akan } \\
\text { masuk } & \text { sudah } \\
\text { sesuai } & \text { dengan } \\
\text { spesifikasi yang di } \\
\text { tentukan }\end{array}$ & 435 & $10,77 \%$ \\
\hline 6 & $\begin{array}{lr}\text { Suatu } & \text { paket yang } \\
\text { keluar } & \text { sudah } \\
\text { sesuai } & \text { dengan } \\
\text { spesifikasi yang di } \\
\text { tentukan }\end{array}$ & 382 & $9,46 \%$ \\
\hline
\end{tabular}

\begin{tabular}{|c|c|c|c|}
\hline 7 & $\begin{array}{l}\text { Kualifikasi } \\
\text { protokol lebih } \\
\text { spesifik dalam } \\
\text { opsional perintah } \\
\text { access control list } \\
\text { (ACL) }\end{array}$ & 441 & $10,92 \%$ \\
\hline 8 & $\begin{array}{lr}\text { Access control list } \\
(A C L) & \text { akan } \\
\text { mencatat } & \text { log } \\
\text { untuk } & \text { setiap } \\
\text { kondisi } & \text { yang } \\
\text { memenuhi } & \\
\text { statement } & \\
\end{array}$ & 401 & $9,93 \%$ \\
\hline & Total Skor & 3180 & $78,71 \%$ \\
\hline & Total Skor Ideal & 4040 & \\
\hline & Rata-rata Skor & 397,5 & \\
\hline
\end{tabular}

Berdasarkan tabel 7 di atas, pernyataan responden mengenai Access Control List (ACL) diperoleh kontribusi sebesar $78,71 \%$ dari total skor ideal, besarnya skor rata-rata yang diperoleh adalah 397,5. Mengacu pada tabel 3.5 rentang skala, total skor 397,5 berada pada kisaran skala ke empat 343,8 - 424,6 (Husein Umar, 2011:164). Jadi dapat disimpulkan bahwa penggunaan Access Control List (ACL) dalam jaringan komputer pada perusahaan di Kawasan Batamindo Industrial Park Batam adalah Baik.

\section{KESIMPULAN}

Berdasarkan hasil dalam penelitian ini dapat ditarik kesimpulan bahwa penggunaan Access Control List (ACL) dalam jaringan komputer pada perusahaan di Kawasan Batamindo Industrial Park Batam adalah Baik.

\section{DAFTAR PUSTAKA}

[1]Rafiudin, Rahmat. 2006.Membangun Firewall dan Traffic Filtering Berbasis CISCO, C.VAndi Offset, Yogyakarta.

[2]Nazir, Moh, Ph.D. 2005. Metode Penelitian, Ghalia Indonesia. Jakarta. 
[3]Rafiudin, Rahmat. 2005. Konfigurasi Security Jaringan Cisco. PT Elex Media Komputindo, Jakarta.

[4]Sofana. Iwan. 2012. CISCO CCNP dan Jaringan Komputer. Informatika, Bandung.

[3]Sugiyono. (2012). Metode Penelitian Manajemen. Edisi pertama. ALFABETA, Bandung.

[5]Umar, Husein., 2011., Metode Penelitian untuk Skripsi dan Tesis Bisnis, Edisi 2, PT. Rajagrafindo Persada, Jakarta. 